Pediat. Res. 6: 687-692 (1972)

Chloramphenicol fibroblasts

cytochrome oxidase respiration, cellular

erythromycin

tetracycline

\title{
Effect of Antibiotics on Respiration in Human Cells
}

\author{
Donald A. Pious ${ }^{[23]}$ and Pamela Hawley \\ Department of Pediatrics, University of Washington, Seattle, Washington, USA
}

\begin{abstract}
Extract
Chloramphenicol (CAP), chloramphenicol succinate (CAP-S), tetracycline (TET), and erythromycin (EM) inhibited synthesis of a mitochondrial enzyme, cytochrome oxidase, in cultured human fibroblasts; the $50 \%$ inhibitory concentrations were $7.5,13,18$, and $350 \mu \mathrm{M}$ respectively, or $2.4,4.1,8$, and $250 \mu \mathrm{g} / \mathrm{ml}$. In fibroblasts grown in CAP-S, cytochrome oxidase declined exponentially with a halflife of approximately 2.0 days. Oxygen uptake, on the other hand, was unchanged for the first 24-48 hr of exposure to CAP-S, and then declined, but at a much slower rate than did cytochrome oxidase; after 7 days, cytochrome oxidase activity was $6 \%$ of the control value, whereas oxygen uptake was $50 \%$ of control. From the kinetic data we conclude that cytochrome oxidase is not normally rate-limiting in cellular respiration, but that, after a period of exposure to CAP-S, an enzyme whose synthesis is inhibited by CAP-S becomes rate-limiting. This enzyme is not cytochrome oxidase, but more likely another component of the respiratory chain. Both $\mathrm{CAP}$ and TET inhibited cytochrome oxidase accumulation in non-growing as well as in growing fibroblasts, with enzyme levels declining to $50 \%$ of control values in $48 \mathrm{hr}$; after that time, a new, lower steady state level of enzyme was attained. Oxygen uptake was not inhibited in fibroblasts by short (4-hr) exposure to CAP, CAP-S or TET in concentrations up to $1 \mathrm{~mm}$.
\end{abstract}

\section{Speculation}

Antibiotics which act by inhibiting bacterial protein synthesis also inhibit mitochondrial enzyme synthesis in virtually all eukaryotic organisms and cells. The rarity of obvious clinical sequellae in patients receiving these agents is explained by the fact that cytochrome oxidase and other components of the respiratory chain, the synthesis of which is inhibited by these agents, are not normally rate-limiting in cellular respiration. After prolonged exposure to these antibiotics, a rate-limiting level of a component of the respiratory chain is reached, but its activity declines slowly and the restriction in respiratory capacity is consequently modest.

\section{Introduction}

Antibiotics such as CAP, the tetracyclines, and the macrolides, which exert their antibacterial effect by inhibiting bacterial protein synthesis, also inhibit mitochondrial protein synthesis in eukaryotic cells. It has been shown, for example, that CAP specifically inhib- its amino acid incorporation by isolated mitochondria, but not by a microsomal incorporating system from the same source [10, 14]. Inhibition of mitochondrial protein synthesis by CAP leads to a decline in the activity of cytochrome oxidase [16] and in the absorption bands of cytochromes $a a_{3}, b$, and $c_{1}[1,3]$. It is 
not presently known whether changes in respiratory enzyme levels occur in patients receiving these agents and, if so, whether these changes adversely affect patients. The answer to the latter depends to a large extent on whether the reduction in enzyme levels caused by these agents is associated with a reduced cellular respiratory capacity.

To study this question, we have determined the kinetics of decay of respiratory enzyme accumulation in growing and non-growing human fibroblasts exposed to antibiotics, as well as the kinetics of decay of celluIar respiratory capacity. Our results indicate that these agents, and CAP and TET in particular, are potent inhibitors of respiratory enzyme accumulation. However, we find that the enzymes whose synthesis is inhibited by these antibiotics are not normally rate-limiting in cellular respiration. Only after a prolonged period of exposure to antibiotics do these enzymes (or enzyme) become rate-limiting. The relation of these and other findings to the clinical toxicity of these agents is considered.

\section{Materials and Methods}

\section{Cells and Culture Methods}

Diploid human fibroblast strains initiated in our laboratories [18] were used for these studies. Medium 199 supplemented with $20 \%$ fetal bovine serum was the growth medium for all experiments. Cells were grown in prescription bottles and cylindrical roller vessels. Tetracycline, chloramphenicol succinate, and erythromycin were dissolved in distilled water before addition to the medium. Chloramphenicol was dissolved in ethanol and then added to the medium at a ratio of $20 \lambda$ per $10 \mathrm{ml}$ medium; this concentration of ethanol did not affect cell growth, respiration, or enzyme level.

\section{Respiration}

Oxygen uptake of whole cells was determined polarographically at $37^{\circ}$ on an Oxygraph [20] with a Clark electrode [2]. Cells, harvested from roller bottles by scraping, were washed once at $0^{\circ}$ in balanced saline, then suspended in "Respiratory Buffer" [9] prewarmed to $37^{\circ}$. All tricarboxylic acid substrates were added to final concentrations of $3 \times 10^{-3} \mathrm{M}$. Where indicated, respiration was uncoupled by the addition of dinitrophenol (DNP) dissolved in $3 \lambda$ of ethanol to a final concentration of $20 \mu \mathrm{M}$. One unit of specific activity equals 1 nanomole $\mathrm{O}_{2}$ taken up/mg protein $/ \mathrm{min}$.

\section{Enzyme Assay}

Cytochrome oxidase specific activity (activity per milligram protein) was determined by following the rate of disappearance of reduced cytochrome $c$ spectrophotometrically after addition of a lysate of whole cells prepared with deoxycholate, as described previously [19]. One unit of specific activity equals 1 nanomole cytochrome $c$ oxidized $/ \mathrm{mg}$ protein $/ \mathrm{min}$.

\section{Protein}

Protein was determined by the method of Lowry et al. [12].

\section{Results}

\section{Effects of Antibiotics on Cytochrome Oxidase Accumu-} lation in Growing Cells

The effects of CAP, TET, and EM were studied by growing newly passaged cells in graded concentrations of the antibiotic for 5 days and then assaying for cytochrome oxidase specific activity. CAP, CAP-S, and TET all markedly inhibited cytochrome oxidase accumulation after 5 days of exposure (Fig. 1); EM was considerably less inhibitory. The $50 \%$ inhibitory concentrations $(\mu \mathrm{M})$ of the antibiotics were: CAP, 7.5; CAP-S, 13; TET, 18; and EM, 350. A plateau at approximately $10 \%$ of control activity appeared with concentrations of CAP $>40 \mu \mathrm{M}$ and of CAP-S $>80 \mu \mathrm{M}$; this plateau value is presumed to reflect the result of complete inhibition of cytochrome oxidase synthesis by these antibiotics.

Kinetics of Decline of Respiratory Activity and Cytochrome Oxidase Activity of Cells Grown in CAP-S.

The aim of these experiments was to determine whether growth in antibiotics affected respiratory capacity as well as cytochrome oxidase activity and, if so, to compare the kinetics of decline of respiratory capacity and cytochrome oxidase activity. The results of a typical experiment are depicted in Figure 2. When cells were grown in $620 \mu \mathrm{M}$ CAP-S, cytochrome oxidase specific activity declined exponentially with a half-life of approximately 2.0 days. In contrast, oxygen uptake was not reduced over the first $24 \mathrm{hr}$; thereafter there was a gradual decline, but at a considerably slower rate than that of cytochrome oxidase activity. Thus, at 7 days cytochrome oxidase activity had declined to $6 \%$ of the control value, while oxygen uptake was $50 \%$ of control. To rule out the possibility that the decline in respiration caused by CAP-S reflected a change in res- 


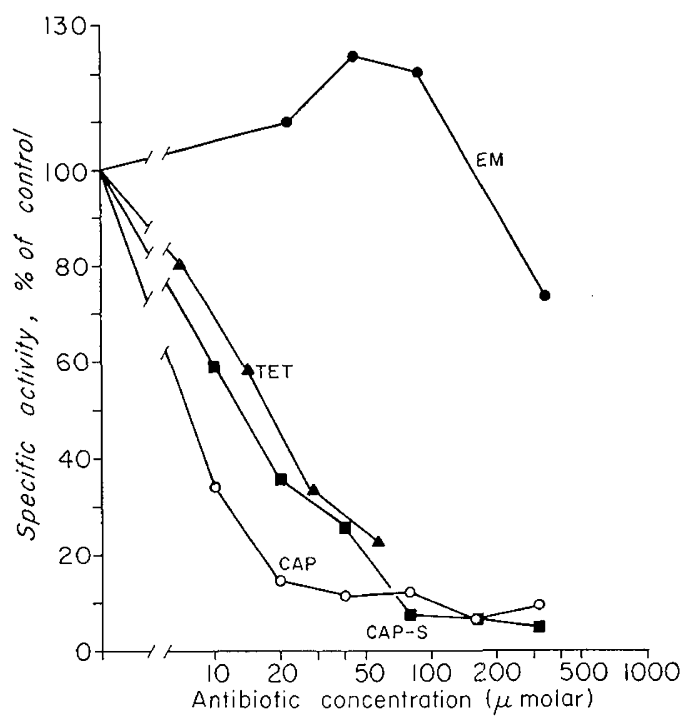

Fig. 1. Effect of antibiotics on cytochrome oxidase levels in growing fibroblasts. Newly seeded cultures of fibroblasts were incubated with antibiotics for 5 days. Protein per culture increased 6 -fold in controls and 2- to 4-fold in cultures with antibiotics during the 5 days. Control (100\%) values for cytochrome oxidase specific activity for each experiment were: CAP, 10.8; CAP-S, 13.3; TET and EM, 9.0. CAP: Chloramphenicol, CAP-S: chloramphenicol succinate, $T E T$ : tetracycline, $E M$ : erythromycin.

piratory control rather than in respiratory capacity, respiration in each sample was uncoupled with DNP and the rate of uncoupled respiration was then determined. The effect of CAP-S was the same on respiration uncoupled by DNP as on respiration in the absence of the uncoupler.

In order to be certain that CAP-S did not interfere with the measurement of cytochrome oxidase activity, CAP-S (final concentration, $600 \mu \mathrm{M}$ ) was added to a fibroblast lysate in a standard cytochrome oxidase assay mixture. The presence of CAP-S did not affect measurement of activity (Table I).

\section{Effect of Antibiotics on Enzyme Accumulation in Sta- tionary Cells}

It is clear from the preceding experiments that cytochrome oxidase activity declines rapidly in dividing cells grown in antibiotics. However, in view of the fact that some cell types divide rarely in vivo or not at all, it was of interest to determine whether changes in the levels of respiratory enzymes occur in nondividing cells exposed to antibiotics. To study this question, fibroblasts were grown to confluent monolayers. At this time cell division virtually ceases due to contact inhibition, unless fresh serum is added. Antibiotics were then added without medium change, and cytochrome oxidase activity was followed. Enzyme activity fell to ap- proximately $50 \%$ of the control value in the first $48 \mathrm{hr}$ after exposure to CAP-S or TET (Fig. 3). However, after $48 \mathrm{hr}$, the enzyme level reached a new steady state at about $50 \%$ of the control value, and did not change thereafter.

\section{Oxygen Consumption of Cells Exposed to Antibiotics for 4 Hours}

In some mammalian cells, CAP inhibits respiration directly, in addition to inhibiting synthesis of respira-

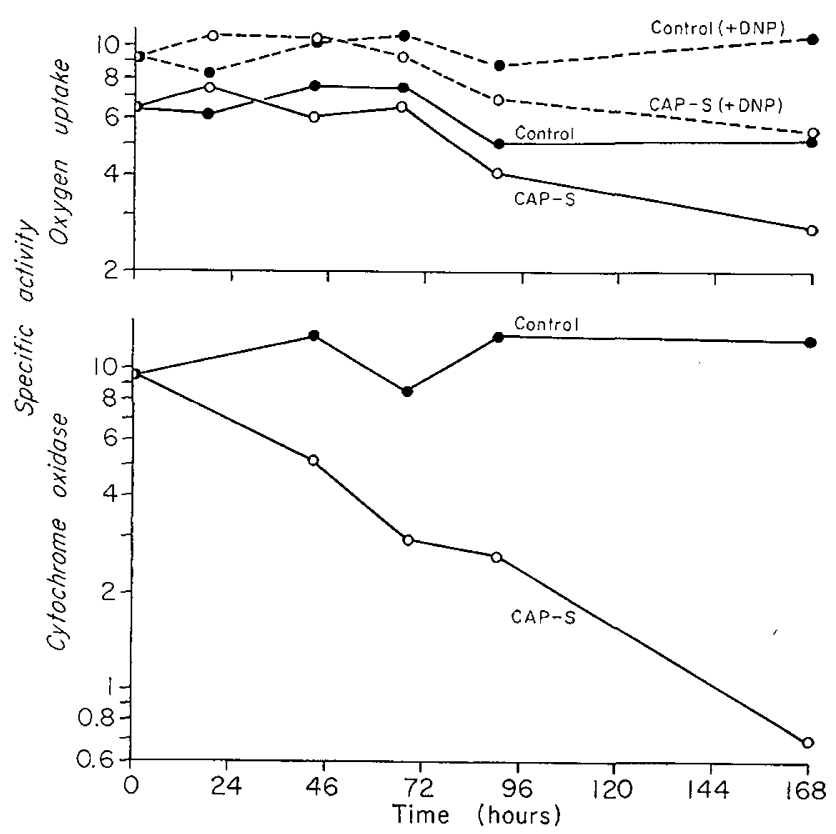

Fig. 2. Kinetics of decline of cytochrome oxidase and of oxygen uptake in fibroblasts grown in chloramphenicol succinate (CAP-S). Fibroblasts were harvested from monolayer cultures by scraping. Cytochrome oxidase specific activity and oxygen uptake were measured on a portion of the cells, and the remainder were seeded into roller vessels with fresh growth medium. Half the cultures received CAP-S to a final concentration of $200 \mu \mathrm{g} / \mathrm{ml}(620 \mu \mathrm{M})$. At the indicated times, cultures were assayed for enzyme activity and oxygen uptake. Oxygen uptake was determined in the presence of all tricarboxylic acid substrates at concentrations of $3 \times$ $10^{-3} \mathrm{M}$. Dinitrophenol (DNP) was then added to the polarograph chamber and the ensuing rate was determined. Protein per culture increased 7.6-fold from the beginning to the end of the experiment in the control cultures, and 3.6-fold in the CAP-S cultures.

Table I. Effect of chloramphenicol succinate (CAP-S) on cytochrome oxidase activity ${ }^{1}$

\begin{tabular}{cc}
\hline CAP-S in assay mixture, $\mu \mathrm{M}$ & Cytochrome oxidase specific activity \\
\hline 0 & $10.0 \pm 0.9$ \\
660 & $9.4 \pm 0.1$ \\
\hline
\end{tabular}

${ }^{1}$ Assays of fibroblast lysates were made in the presence and absence of CAP-S. 
tory enzymes $[4,13]$. To determine whether the phenomenon of direct inhibition of respiration occurs in human fibroblasts, cells in stationary phase were incubated for $4 \mathrm{hr}$ in increasing concentrations of antibiotics; they were then harvested and oxygen consumption was determined. In some experiments, antibiotics were also added to the polarograph chamber. Respiration was not inhibited by CAP, CAP-S, or TET at concentrations approaching $1 \mathrm{~mm}$ (Table II). We have previously found that cytochrome oxidase synthesis is inhibited within $3 \mathrm{hr}$ after exposure to CAP [16], which indicates that the 4-hr exposure time used in these experiments was sufficient for uptake of CAP by mitochondria. Addition of antibiotics to the polarograph chamber as well as for the 4-hr incubation period did not alter the results, which indicates that washout of antibiotics during harvesting does not account for the lack of inhibition.

\section{Discussion}

These studies indicate that broad-spectrum antibiotics which act by inhibiting bacterial protein synthesis are potent inhibitors of mitochondrial enzyme synthesis in human cells. The concentrations of CAP, CAP-S, and TET that inhibited cytochrome oxidase accumulation are roughly $1 / 10,1 / 5$, and 2 times the levels present in the plasma of humans on standard dosage schedules [5]. The significance of these findings to patients receiving these agents is not likely to depend primarily

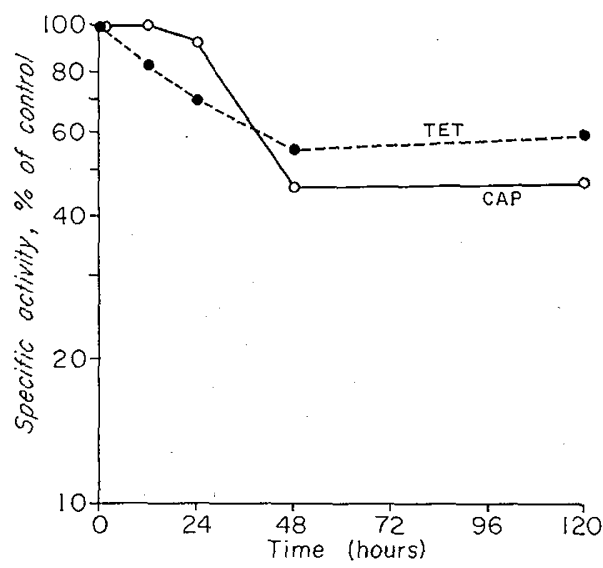

Fig. 3. Effect of antibiotics on cytochrome oxidase levels in nongrowing fibroblasts. Fibroblasts were grown to monolayers. At 0 time, cultures received either (1) tetracycline (TET) to a final concentration of $100 \mu \mathrm{g} / \mathrm{ml}(230 \mu \mathrm{M})$; (2) chloramphenicol suc. cinate (CAP-S) to $200 \mu \mathrm{g} / \mathrm{ml}(620 \mu \mathrm{M})$; or (3) nothing. No growth occurred during the experiment; protein per culture decreased $10 \%$ in control cultures and $20-40 \%$ in antibiotic-treated cultures over the course of the experiment. Control $(100 \%)$ value for cytochrome oxidase specific activity was 9.6 .
Table 1I. Oxygen uptake of cells exposed to antibiotics for 4 hours $^{1}$

\begin{tabular}{lccc}
\hline Antibiotic & $\begin{array}{c}\text { Concentra- } \\
\text { tion, } \mu \mathrm{MI}\end{array}$ & $\begin{array}{c}\text { Oxygen uptake, } \\
\text { nmoles/mg } \\
\text { protein/min }\end{array}$ & $\begin{array}{c}\% \text { of } \\
\text { control value }\end{array}$ \\
\hline None & - & 6.51 & $(100)$ \\
GAP & 872 & 7.94 & 122 \\
CAP & 872 & $5.50^{3}$ & 84 \\
CAP-S & 930 & 7.65 & 118 \\
& & & \\
None & - & 5.98 & $(100)$ \\
TET & 225 & 7.74 & 129 \\
TET & 225 & $7.74^{3}$ & 129 \\
TET & 900 & 5.54 & 91 \\
TET & 900 & $9.66^{3}$ & 161 \\
\hline
\end{tabular}

${ }^{3}$ Cultures in stationary phase were incubated with antibiotics for $4 \mathrm{hr}$ at $37^{\circ}$, then harvested. Where indicated, antibiotics were added to the polarograph chamber to final concentrations equivalent to those to which the cells had previously been exposed. Oxygen uptake was determined in the presence of all tricarboxylic acid substrates at concentrations of $3 \times$ $10^{-3} \mathrm{M}$. . . : :

2 CAP: chloramphenicol, CAP-S : chloramphenicol succinate, TET: tetracycline.

${ }^{3}$ Antibiotic was also added to polarograph chamber.

on the reduction in enzyme levels per se, however, but on whether such changes result in decreased cellular respiratory capacity. Our data demonstrate that oxygen uptake was sensitive to inhibition of enzyme synthesis by antibiotics. However, the kinetics indicate that the relation between decline in enzyme level and in respiratory capacity is complex. Although we have previously shown that the level of cytochrome oxidase activity fell within several hours during exposure of fibroblasts to CAP [16], there was a lag of 24-48 hr between exposure to CAP and decline in oxygen uptake (Fig. 2). The presence of this lag suggests that the enzymes whose synthesis is inhibited by antibiotics, namely cytochromes $a a_{3}, b$, and $c_{1}$ [3], are not normally rate-limiting in respiration. However, after 24-48 hours of inhibition of enzyme synthesis, a level of enzyme was reached which became rate-limiting, as indicated by the decline in oxygen uptake from that point on. The fact that the rate of fall of respiration was markedly slower than that of cytochrome oxidase suggests that a component of the respiratory chain with a rate of degradation slower than that of cytochrome oxidase, possibly cytochrome $b$ or $c_{1}$, had become ratelimiting.

No direct answer can be given at present to the question of whether humans receiving these antibiotics undergo inhibition of respiratory enzyme synthesis and, if so, whether these changes have adverse effects. However, several considerations are pertinent. First, 
although cultured human cells are clearly not human beings, cultured human fibroblasts faithfully reflect the human karyotype [8], genome [11], and function of fibroblasts in vivo [7]. Thus the present data make it seem likely that human mitochondria are sensitive to these antibiotics, as are the mitochondria of all other eukaryotic organisms and cell types which have been studied, with the single possible exception of brain mitochondria [6]. Second, the effects of antibiotics on respiratory enzyme synthesis occur in the intact animal as well as in cultured cells: rats, given CAP and oxytetracycline in vivo and then killed, had decreased levels of cytochromes $a a_{3}, b$, and $c_{1}[1,3]$. Thus there is reason to believe that humans receiving these antibiotics may be subject to reduction in levels of respiratory enzymes. However, with the exception of the "Gray" syndrome which occurs in premature neonates with high plasma levels of CAP [17], significant respiratory effects of these antibiotics have not been recognized clinically. We propose that the reason for the apparent rarity of clinically detectable effects of these antibiotics on cellular respiration is related to the evidence presented here that the enzymes whose synthesis is inhibited by antibiotics are not rate-limiting in respiration in human cells. When, after prolonged exposure to antibiotics, a rate-limiting level of respiratory enzyme is reached, its rate of degradation is quite slow and the overall restriction in respiratory capacity is modest.

Both CAP and TET were found to reduce the level of cytochrome oxidase in nondividing as well as in dividing cells. These findings are indicative of a degradative mechanism for cytochrome oxidase. Thus cells which do not normally divide or which divide infrequently in vivo-myocardial cells, for example-may be subject to change in enzyme level following exposure to these drugs, although the rate of fall in nondividing cells (Fig. 3) was only half that in growing cells (Fig. 2) in these experiments. An unexpected finding was the leveling off in enzyme specific activity which was regularly found in nondividing cells exposed to antibiotics for more than $48 \mathrm{hr}$. The reason for this leveling off is not clear at present, but it is of interest that stationary phase was achieved in our experiments by exclusion of fresh serum, and that Mellman et al. have found that fresh serum is necessary to sustain degradation of another enzyme (catalase) in a cell culture system [15].

\section{Summary}

The accumulation of the respiratory enzyme cytochrome oxidase was strongly inhibited in cultured human fibroblasts by CAP and TET and, to a lesser extent, by EM. This effect of antibiotics was noted in both growing and nongrowing (stationary phase) cells. The 50\% inhibitory concentrations for CAP and TET were comparable to plasma levels in patients on therapeutic regimens. Cellular oxygen uptake declined in cells grown in CAP, but the rate of decline was considerably slower than that of cytochrome oxidase. The results indicate that the components of the respiratory chain whose synthesis is inhibited by these antibiotics are not normally rate-limiting in cellular respiration. This may account for the rarity with which respiratory effects of these agents are apparent clinically.

\section{References and Notes}

1. De Vries, and Kroon, A. M.: Biogenesis of mitochondria. VIII. The effect of chloramphenicol and oxytetracycline on the biogenesis of mammalian mitochondria. Biochim. Biophys. Acta, 204: 531 (1970).

2. Estabrook, R.: Mitochondrial respiratory control and the polarographic measurement of $\mathrm{ADP}: \mathrm{O}$ ratios. In: S. Colowick and N. Kaplan: Methods in Enzymology, Vol. X, p. 41. (Academic Press, New York, 1967).

3. Firkin, C. R., AND Linnane, A. W.: Biogenesis of mitochondria. VIII. The effect of chloramphenicol on regenerating rat liver. Exp. Cell. Res., 55: 68 (1969).

4. Freeman, K. B., and Haldar, D.: The inhibition of NADH oxidation in mammalian mitochondria by chloramphenicol. Biochem. Biophys. Res. Commun., 28: 8 (1967).

5. Goodman, L. S., and Gilman, A.: The Pharmacological Basis of Therapeutics, Chapters 59 and 60. (Macmillan, New York, 1970).

6. Gordon, M. W., and Deanin, G.: Protein synthesis by isolated rat brain mitochondria and synaptosomes. J. Biol. Chem., 243: pt. 4: 4222 (1968).

7. Green, H., Goldberg, B., and Todaro, G.: Differentiated cell types and the regulation of collagen synthesis. Nature, 212: 631 (1966).

8. Hayflick, L., and Moorhead, P.: The serial cultivation of human diploid cell strains. Exp. Cell Res., 25: 585 (1961).

9. Koboyashi, S., Hagihara, B., Masuzumi, M., and OKunuki, K.: Preparation and properties of mitochondria from mammalian cell lines cultured in vitro. Biochim. Biophys. Acta, 113: 421 (1966).

10. Kroon, A. M.: Protein synthesis in mitochondria. III. On the effects of inhibitors on the incorporation of amino acids into protein by intact mitochondria and digitonin fractions. Biochim. Biophys. Acta, 108: 275 (1965).

11. Krooth, R. S., AND SELL, E. K.: The action of Mendelian genes in human diploid cell strains. J. Cell Physiol., 76: 311 (1970).

12. Lowry, O. H., Rosebrough, W. J., Farr, A., And Randall, R. $\mathrm{J}$ : Protein measurement with the Folin reagent. J. Biol. Chem., 193: 265 (1951).

13. Mackler, B., and Haynes, B.: The electron transport systems of heart muscle and yeast: site of inhibition by chloramphenicol. Biochim. Biophys. Acta, 197: 317 (1970).

14. MAGER, J.: Chloramphenicol and chlortetracyline inhibition of amino acid incorporation into proteins in a cell-free system 
from Tetrahymena pyriformis. Biochim. Biophys. Acta, 38: 150 (1960).

15. Mellman, W., Hayflick, L., and Shimke, R.: Personal communication.

16. Prous, D. A.: Induction of cytochromes in human cells by oxygen. Proc. Nat. Acad. Sci., 65: 1001 (1970).

17. Prous, D. A., And Hakami, N.: Defects in respiratory enzyme synthesis induced by chloramphenicol: a mechanism for the "Gray" syndrome (Abstract). Society for Pediatric Research. (1968).

18. Pious, D. A., Hamburger, R. N., and Mills, S. E.: Clonal growth of primary human cell cultures. Exp. Cell Res., 33: 495 (1964).
19. Pious, D. A., Susor, W. A., Benson, R., And Rutter, W. J.: Independent regulation of cytochromes and glycolytic enzymes in human fibroblasts. J. Cell Physiol., in press. (1972).

20. Gilson Medical Electronics, Inc., Middleton, $W$ is.

21. Dr. Pious is the recipient of Public Health Service Research Career Development Award no. 2K3 HD31 721-06.

22. Supported by Grant no. GM 15883 from the National Institute of General Medical Sciences.

23. Requests for reprints should be addressed to: Donald A. Pious, M.D., Department of Pediatrics, University of Washington, Seattle, Wash. 98195 (USA).

24. Accepted for publication March 13, 1972. 